\title{
Postoperative analgesic effect of intrathecal neostgmine added to bupivacaine for adult patients undergoing lower limb orthopedic surgery
}

\begin{abstract}
Background: Several additives have been suggested to enhance analgesic effect of local anesthetic agents to decrease the adverse effects and increase the degree of satisfaction

Objective: To assess postoperative analgesic effect of intrathecal neostigmine added to bupivacaine in comparison with bupivacaine alone for adult patients undergoing Lower limb Orthopedic Surgery at Tikur Anbessa specialized Hospital, Addis Ababa, Ethiopia, from January 1 to February 30, 2017 G.C.

Methods: This institutional based prospective observational cohort study was conducted among 60 adult patients scheduled for elective lower limb orthopedic surgery under spinal anesthesia and grouped in to bupivacaine group based on independent decision of responsible anesthetist. Patient's vital signs were taken intraoperativley. Postoperatively duration \& consumption of analgesia, first analgesia request as well as severity of pain using $100 \mathrm{~mm}$ visual analogue scale score were assessed over $24 \mathrm{hrs}$. Normality of the data was checked using Shapiro-Wilk test and analyzed using student $t$ test for normal distributed data and chi-square test for categorical data. Non- parametric data was analyzed using Mann-Whitney U test with $95 \% \mathrm{CI}$ and p-value less than 0.05 is considered as statistically significant.
\end{abstract}

Results: Bupivacaine neostigmine group $(\mathrm{BN}, \mathrm{n}=30)$ compared with bupivacaine only group (BS, $\mathrm{n}=30$ ) which was presented by mean \pm standard deviation, time of the first analgesic request in neostigmine and bupivacaine group was $(377.60 \pm 9.14)$ and $(230.07 \pm 17.11)$ in minute respectively, $\mathrm{p}<0.001$. Morever total amount of tramadol consumption was also significantly different between the two groups that was presented by median (inter quartile range), which was $50(50) \mathrm{mg}$ in neostigmine group vs. $100(50) \mathrm{mg}$ in bupivacaine group. The visual analogue scale score also reduced at $1 \mathrm{hr}, 2 \mathrm{hrs}, 3 \mathrm{hrs}$, $4 \mathrm{hrs}, 5 \mathrm{hrs}$ and $6 \mathrm{hrs}$ in neostigmine group.

Conclusion and recommendation: Addition of $25 \mathrm{mcg}$ intrathecal neostigmine as an adjuvant to $15 \mathrm{mg}$ bupivacaine for elective lower limb orthopedic surgery increased first analgesia request time, reduced postoperative analgesia consumption and with minimal hemodynamic changes and side effects. We recommend that the use of intrathecal neostigmine combined with bupivacaine for lower limb surgery in our setup.

Keywords: spinal anesthesia, lower limb orthopedic surgery, intrathecal neostigmine, postop analgesia
Volume 6 Issue I - 2018

\author{
Kassaw Moges,' Fentahun Tarekegn,' \\ Betelhem Girma' \\ 'Department of Anesthesia, College of Medicine and Health \\ Sciences, Addise Ababa University, Ethiopia \\ 2Department of Anesthesia, College of Medicine and Health \\ Sciences, Bahir Dar University, Ethiopia
}

Correspondence: Fentahun Tarekegn, Department of Anesthesia, College of Medicine and Health Sciences, Bahir Dar University, Ethiopia, Tel +25 1913824072,

Email tarekegnfentahun@gmail.com

Received: July 05, 2017 | Published: January 24, 2018

\section{Introduction}

Anesthetists are leaders in the development of pain services in the current era. Pain has been defined as "an unpleasant sensory and emotional experience associated with actual or potential tissue damage". ${ }^{1}$ Procedural pain being the acute type which has probability of progressing to chronic pain unless intervened properly. ${ }^{2}$ Postoperative pain is associated with catecholamine release, and the central sensitization issue posed to be among the mechanisms concerned with the persistence of postoperative pain. The aim of good post-operative analgesia is to produce a long lasting, continuous effective analgesia with minimum side effects. ${ }^{3}$ Neuraxial blocks have been introduced to produce superior analgesia and decrease the blood loss and the incidence of deep venous thrombosis (DVT), pulmonary embolism, and to minimize the adverse effects of general anesthesia and improve the patients' outcomes. Better pain control may result in an earlier hospital discharge of the postoperative period. ${ }^{4}$ Intrathecal (IT) neostigmine has been used as an adjunct to spinal anesthesia (SA) for the prevention of acute perioperative pain. It has been shown to potentiate opioid analgesia while reducing undesirable side effects such as somnolence and respiratory depression. Intrathecal neostigmine with bupivacaine caused a prolonged time to the first analgesic request and its use was not associated with any side effects. ${ }^{4-6}$ Neostigmine is an anticholinesterase agent which increases the acetylcholine concentrations at cholinergic synapses. Spinal neostigmine apparently activates descending pain inhibitory systems that rely on a spinal cholinergic interneuron, which is extremely efficient for alleviating somatic pain. ${ }^{7}$ 
Pain is the most important cause of unintended hospital admissions following Spinal anesthesia with source of dissatisfaction. ${ }^{8}$ Spinal anesthesia (SA) is the most commonly used anesthetic technique for lower limb surgeries despite short duration of action when local anesthetic is used alone. ${ }^{9}$ There are controversies concerning effective intrathecal doses of neostigmine with lesser side effects. Studies recommend intrathecal neostigmine doses to be given as an adjuvant ranging from $25 \mathrm{~g}$ to $150 \mathrm{~g}^{10}$ even though a dose-dependent increases the incidence of postoperative nausea vomiting (PONV). ${ }^{1-11}$ Spinal anesthesia with bupivacaine is routinely done in Tikur Anbessa specialized hospital, Ethiopia by master anesthetists. The same study is not conducted about the analgesic efficacy of neostigmine as an adjuvant in our country. The aim of this study was to assess postoperative analgesic effect of intrathecal neostigmine added to bupivacaine in comparison with bupivacaine alone for adult patients undergoing lower limb Orthopedic Surgery. ${ }^{12-14}$

\section{Methods}

\section{Study designs and patients}

There was an institution based prospective cohort study design conducted from January 1 to February 30, 2017 in Tikure Anbesa Hospital.

A. Inclusion criteria: Patient's age $>18$ who had ASA I-II physical status, with lower limb orthopedic surgery under sub arachinoid block, and 25 microgram neostigmine prearranged for the block.

B. Exclusion criteria: Spinal anesthesia using local anesthetics other than bupivacaine, patient refusal, sedation, American society of Anesthesiologist (ASA) class III\& IV, and communication failure. ${ }^{15-17}$

According to the results of Indian study, the mean duration of analgesia and standard deviation were $308.76 \pm 127.40$ when neostigmine was co-administered with bupivacaine, in the contrary bupivacaine alone was mean \pm SD $(229.52 \pm 59.16),{ }^{9}$ which means $\mu_{1}$ (308.76), $\sigma_{1}(127.40), \mu_{2}(229.52)$ and $\sigma_{2}(59.16)$ with an alpha error of 0.05 at a power of $80 \%$, when this value is incorporated into the mean comparison formula for continuous outcome,

$$
n_{1}=\frac{\left(\sigma_{1}^{2}+\sigma_{2}^{2}\right)\left(Z_{-}^{\alpha}+Z_{\beta}\right)^{2}}{\left(\mu_{1}-\mu_{2}\right)^{2}} \text { Ratio of exposed to unexposed (1:1) }
$$

$$
n=\frac{\left((127.4)^{2}+(59.16)^{2}\right)(1.96+0.84)^{2}}{(308.76-229.52)^{2}}
$$

$\mathrm{n}=25$, When $20 \%$ of contingency is included for dropouts, the total sample was 60 patients

$$
\mathrm{n}=30 \text { patients per group was required. }
$$

\section{Study variables}

The dependent variable is the postoperative pain which could be assessed by visual analogue scale (VAS), postoperative analgesic consumption, and the first analgesic request time. Independent variables included age, sex, American society of anesthesiologists
(ASA) status, duration of surgery, onset of sensory and motor block, and duration of motor block.

i. VAS: Visual analogue scale which is a method of pain assessment determined by the patient making a mark of their pain intensity on a line which is 100 millimeter long. ${ }^{18}$

ii. Time for first analgesia request: initial time in which patients need pain treatment postoperatively. ${ }^{19}$

iii. Total analgesic consumption: Defined as type and amounts of analgesic drugs given to the patient within $24 \mathrm{hrs}$ postoperatively.

iv. Bromage scale: a method of assessing grade of motor block (' 0 '=full movement of hip, knee and ankle; $1=$ ability to flex knees but no hip movement; $2=$ unable to flex knees, but no problems with ankle movement; $3=$ no movement possible with any of the lower extremity joints). ${ }^{16}$

v. Onset of motor block: The time of reaching to Bromage III. ${ }^{20}$

vi. Duration of motor block to recover: when the modified Bromage score is $0 .{ }^{20}$

vii. Onset of sensory block: time elapsed from the end of study solution administration to absence of pinprick sensation at T10 dermatome..$^{21}$

\section{Data collection}

During each procedure, the data collectors observed intraoperative condition of the patient. Post operatively also each patient was interviewed and their charts were also reviewed. Patients in group BN (Bupivacaine with neostigmine) were managed with $25 \mathrm{mcg}$ of intrathecal neostigmine with $15 \mathrm{mg}$ of $0.5 \%$ bupivacaine considered as cases. Another group BS (bupivacaine with saline) was those who had given $15 \mathrm{mg}$ of $0.5 \%$ bupivacaine only. Intraoperative data were collected by one of the trained data collector. Starting from the immediate postoperative time, presence and scale of pain, time for the first analgesic request as well as analgesics need were assessed by another trained data collector. These assessments have been done at $1 \mathrm{hr}, 2 \mathrm{hrs}, 3 \mathrm{hrs}$, $4 \mathrm{hrs}, 5 \mathrm{hrs}, 6 \mathrm{hrs}, 12 \mathrm{hrs}$ and $24 \mathrm{hrs}$ of VAS postoperative period and within $24 \mathrm{hrs}$ of postoperative total analgesic consumption were taken. The categories of patients were identified by the blinded data collector. Before surgery the concept of visual analog scale (VAS) which consists of $100 \mathrm{~mm}$ line with 0 equaling "no pain at all" and 100 equaling "the worst possible pain", was introduced on 100mm VAS line.

\section{Data analysis}

Data was entered into SPSS version 20 software program. Demographic data were analyzed using student $t$ test (for normal distribution variables) and chi-square test (for categorical variables) as appropriate. The data was tested for normality using Shapiro-Wilk normality test. There was normal distribution data for the time of the first analgesic request, total duration of analgesia, repeated VAS measurements and hemodynamic changes as checked using ShapiroWilk test and homogeneity of variance assessed using Levene's test for equality of variances. Therefore, an independent sample t-test was run on the data with $95 \%$ confident interval to analyze measurement of time of the first analgesic request, total duration of analgesia time and VAS measurements. However, total post-operative analgesia consumption was not normally distributed when checked using Shapiro-Wilk test. Therefore, non-parametric Mann-Whitney U test 
was run on the data as well as $95 \%$ confidence interval to analyze with further paired comparison at each time interval. Normally distributed data are presented as mean $\pm \mathrm{SD}$ whereas not normally distributed data presented as median (IQR) and categorical data presented by frequencies (percentages). A p value $<0.05$ was considered statistically significant.

\section{Ethical approval}

Ethical clearance was obtained from school of Medicine department of Anesthesia Ethical Review committee, Addise Ababa college of Medicine and Health science. It was also taken written informed consent from each patient after clear explanation. We gave an opportunity to stop at any time for those who were not willing to participate in the study. Confidentiality was guaranteed with anonymous questionnaires.

\section{Results}

\section{Socio-demographic characteristics of the participants}

A total of 60 patients (30 patients in each group) were included in the study that had been under spinal anesthesia. From this, 30 were cases of bupivacaine with neostigmine $(\mathrm{BN})$ and the other 30 remaining group were control with bupivacaine only. Demographic data age, sex, weight, height, duration of surgery and ASA status were comparable between each group as shown in Table1.

Table I Demographic and anesthetic base line characteristics between BN\&BS group of patients who undergone Lower limb Orthopedic Surgery at Tikur Anbessa specialized Hospital,Addis Ababa, Ethiopia, from January I to February 30, 2017 G.C

\begin{tabular}{llll}
\hline Group & BN & BS & P-value \\
\hline Age in years & $34.67 \pm 16.63$ & $40.13 \pm 19.13$ & 0.242 \\
$\begin{array}{l}\text { Sex, Male } \\
\text { Female }\end{array}$ & $24 / 30=80 \%^{*}$ & $23 / 30=67 \%^{*}$ & - \\
$\begin{array}{l}\text { Weight in } \\
\text { kilogram }\end{array}$ & $60.50 \pm 8020 \%$ & $7 / 30=23 \%^{*}$ & 0.91 \\
$\begin{array}{l}\text { Height in meter } \\
\text { ASA status, }\end{array}$ & $1.64 \pm 0.08$ & $1.65 \pm 0.07$ & 0.647 \\
$\begin{array}{l}\text { ASAI } \\
\text { ASA2 }\end{array}$ & $22(73.3 \%)^{*}$ & $21(70 \%)^{*}$ & 0.774 \\
$\begin{array}{l}\text { Duration of } \\
\text { surgery in } \\
\text { minute }\end{array}$ & $133.98 .7 \%)^{*}$ & $9(30 \%)^{*}$ & - \\
\hline
\end{tabular}

Category: $*=$ frequency, others in mean $\pm S D$

\section{Postoperative pain on VAS score}

There was statistically significant difference on VAS score at $1 \mathrm{hr}, 2 \mathrm{hrs}, 3 \mathrm{hrs}$, $4 \mathrm{hrs}$, $5 \mathrm{hrs}$ and $6 \mathrm{hrs}$ among the groups but there was no statistically significant difference on VAS score at 12 and $24 \mathrm{hr}$ between BN and BS group in Table 2.

\section{The postoperative first analgesic request time}

At postoperative period, an independent $t$ test showed that the first time patients need analgesia was significantly different between two groups, $\mathrm{p}=0.001$. The $\mathrm{BN}$ group had longer time than the control group of BS with (mean $\pm \mathrm{SD})(377.60 \pm 9.14)$ vs. $(230.07 \pm 17.11$, ) minutes.

Table 2 Postoperative visual analogue scale pain scores mean $\pm S D$ in millimeters over the first $24 \mathrm{hrs}$ postoperatively between BN\&BS group of patients who undergone lower limb orthopedic surgery at Tikur Anbessa specialized Hospital, Addis Ababa, Ethiopia, from January I to February 30, 2017 G.C

\begin{tabular}{llll}
\hline Groups & BN & BS & P-value \\
\hline VAS score at Ihrs & 0 & $0.43 \pm 0.67$ & 0.001 \\
VAS score at $2 \mathrm{hrs}$ & 0 & $0.93 \pm 0.94$ & $0.00 \mathrm{I}$ \\
VAS score at $3 \mathrm{hrs}$ & $0.60 \pm 1.04$ & $2.07 \pm \mathrm{I} .46$ & $0.00 \mathrm{I}$ \\
VAS score at $4 \mathrm{hrs}$ & $1.43 \pm \mathrm{I} .19$ & $2.33 \pm \mathrm{I} .18$ & 0.005 \\
VAS score at $5 \mathrm{hrs}$ & $1.67 \pm .80$ & $2.57 \pm 1.19$ & 0.001 \\
VAS score at $6 \mathrm{hrs}$ & $2.00 \pm 0.98$ & $2.73 \pm 0.78$ & 0.002 \\
VAS score at $12 \mathrm{hrs}$ & $2.87 \pm 1.25$ & $2.57 \pm \mathrm{I} .10$ & 0.153 \\
VAS score at $24 \mathrm{hrs}$ & $2.30 \pm 0.99$ & $1.87 \pm 0.90$ & $0.08 \mathrm{I}$ \\
\hline
\end{tabular}

Values are mean $\pm S D$ in centimeter

\section{Characteristics of spinal anesthesia}

There was shorter in onset of sensory block and onset of motor block in BN group than BS group in minutes. The duration of sensor block, motor block and first request for analgesia was prolonged in $\mathrm{BN}$ group than BS group in minutes as shown in Table 3.

Table 3 Characteristic of spinal anesthesia and duration of analgesia between BN\&BS group of patients who undergone Lower limb orthopedic surgery at Tikur Anbessa specialized Hospital, Addis Ababa, Ethiopia, from January I to February 30, 2017 G.C

\begin{tabular}{llll}
\hline Group & BN & BS & P-value \\
\hline $\begin{array}{l}\text { Onset of sensory } \\
\text { block (min) }\end{array}$ & $3.90 \pm \mathrm{I} .2 \mathrm{I}$ & $9.40 \pm 2.14$ & 0.002 \\
$\begin{array}{l}\text { onset of motor } \\
\text { block(minute) }\end{array}$ & $5.70 \pm \mathrm{I} .34$ & $\mathrm{II} .33 \pm 2.22$ & $0.00 \mathrm{I}$ \\
$\begin{array}{l}\text { Duration of motor } \\
\text { block }\end{array}$ & $27 \mathrm{I} .67 \pm \mathrm{II} .17$ & $192.30 \pm 8.02$ & $0.00 \mathrm{I}$ \\
\hline
\end{tabular}

Category references $=$ Mean \pm SD

\section{Postoperative total analgesia consumption}

Since the postoperative $24 \mathrm{hrs}$ of both total diclofenac and total tramadol consumption were not normally distributed as checked by Shapiro-Wilk test, Mann-Whitney $U$ test was used to assess the associations. Patients who received intrathecal neostigmine showed a reduced postoperative total tramadol consumption within $24 \mathrm{hrs}(\mathrm{BN}$ vs. BS group), described as median (IQR) $\mathrm{mg}$, at 24hours 50(100) vs. $100(50), \mathrm{p}<0.001$. Total diclofenac consumption was not statistically significant difference between BN group and BS group within 24hours (BN vs. BS) described as median (IQR) $\mathrm{mg}, 75(75)$ vs. $75(0), \mathrm{p}=0.538$ (Figure 1). 


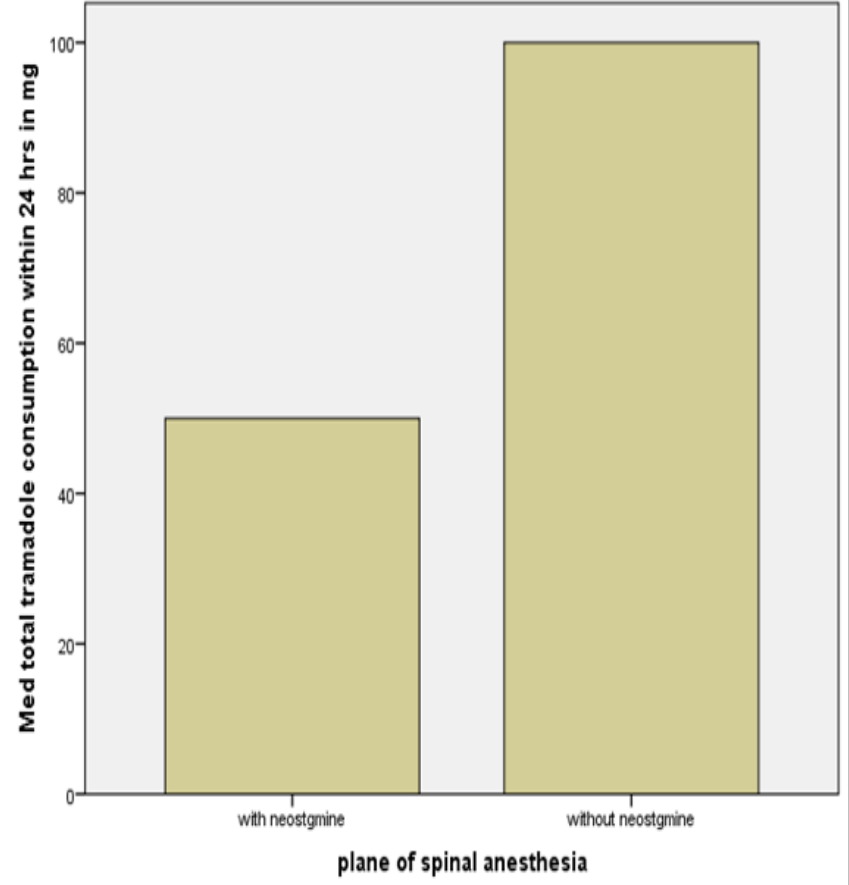

Figure I A bar graph of postoperative total tramadol consumption within $24 \mathrm{hrs}$ in each group of patients who undergone lower limb Orthopedic Surgery at Tikur Anbessa specialized Hospital, Addis Ababa, Ethiopia, from January I to February 30, 2017 G.C.

\section{Discussion}

Effective treatment of pain represents an important component of postoperative recovery. It serves to blunt autonomic, somatic, and endocrine reflexes with a resultant potential decrease in perioperative morbidity. Despite advances in treatment of postoperative pain, many patients still suffer from pain after surgery, probably due to difficulties in balancing postoperative analgesia with acceptable side effects. ${ }^{9}$ Lower limb surgeries are performed under spinal anesthesia with single shot technique compared to epidural and general anesthesia. However, it has limited duration of postoperative analgesia. Additives could be used for the prolongation of duration of motor as well as sensory block to make beneficial in reducing postoperative morbidity. ${ }^{22}$ Studies suggest that neostigmine is an effective adjuvant to prolong the duration of the subarachnoid block and spinal analgesia with better hemodynamic stability ${ }^{23}$ due to synergism between intrathecal neostigmine with local anesthetic agents. ${ }^{11}$ The demographic characteristics (age, sex, weight, height), duration of surgery and ASA status were not statistically significant between the groups which was supported by many studies, $\mathrm{p}>0.05$. $^{7-22}$

In this study, patients in the $\mathrm{BN}$ group had a significant longer time for the first analgesic request compared to BS group, (377.60 \pm 9.14$)$ versus $(230.07 \pm 17.11)$ in minutes respectively with $p=0.001$, which was consistent with Saudi and India studies. ${ }^{23-27}$ However, Middle East Study showed the more prolonged postoperative analgesia request time compared to our study. ${ }^{6}$ This might be due to high dose of bupivacaine $(4 \mathrm{ml})$ they used. In regard to postoperative severity of pain, there was significantly reduced mean VAS score for the first $6 \mathrm{hrs}$ in $\mathrm{BN}$ group than $\mathrm{BS}$ group with $\mathrm{p}$-value $<0.05$ which was comparable with Bhat M.et al and his colleagues study. ${ }^{27}$ This similarity might be related with the wear off analgesic effects of spinal anesthesia in bupivacaine group and the synergistic effect of intrathecal neostigmine with bupivacaine in $\mathrm{BN}$ group continued since the duration of intrathecal neostigmine is expected to stay 6hours. ${ }^{3}$ There was no significant difference in mean VAS scores between BN \& BS groups, $p>0.05$ after 6 shour. $^{9}$ This could be connected with both groups got treatment of diclofenac and tramadol as result of wear of action of intrathecal neostigmine. Patients in $\mathrm{BN}$ group had reduced postoperative total tramadol consumption within $24 \mathrm{hrs}$ compared to BS group, $\mathrm{p}=0.001$. This was comparable with a randomized study conducted by Joshi-Khadke S et al., ${ }^{9}$ and his colleagues showed that intrathecal neostigmine decreased tramadol requirements with $\mathrm{p}$-value $=0.001$. This relationship could be due to patient in $\mathrm{BN}$ group had prolonged duration of analgesia than patient in BS group.

In our study, the onset of highest sensory analgesia had significant difference between $\mathrm{BN}$ and BS group (3.90 \pm 1.21 vs. 9.40 \pm 2.14 respectively) in minutes, $p=0.001$. This was supported by Solainppan $\mathrm{B}$ et al. ${ }^{22}$ study even thought, Gupta $\mathrm{S}$ et al study found that the mean time to reach peak sensory level was earlier with bupivacaine group than neostigmine group in seconds..$^{15}$ The onset of motor blockade

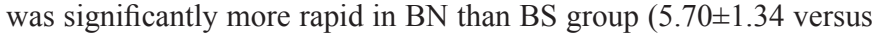
$11.33 \pm 2.22$ respectively) in minutes with grade III motor block. This was consistent with Solainppan B et al..$^{22}$ study. There was also a prolonged duration of motor block in $\mathrm{BN}$ group than $\mathrm{BS}$ group (271.67 \pm 11.17 vs. $192.32 \pm 8.02$ respectively) in minutes. This was somehow longer duration than Bhat $\mathrm{M}$ et al. ${ }^{27} \mathrm{Study}$. This might be due to small dose of bupivacaine they used, (12.5mg of $0.5 \%$ Bupivacaine) compared to our study. ${ }^{22}$ Intrathecal administration of Neostigmine may augment motor block by increasing spinal levels of acetylcholine. Many lower-extremity surgical procedures require muscle relaxation with spinal bupivacaine alone provides only modest motor block. ${ }^{3}$ There was limitation in the study. Patients were not randomized even though the two groups, BN and BS, were comparable in Table 1. It was difficult to have truly blinded data collectors. Because of during data reviewing, they might see groups of the study subjects.

\section{Conclusion}

The result of our study showed that the intrathecal neostigmine with bupivacaine for orthopedic surgery prolonged the first analgesia requested time and reduced severity of pain as well as total analgesia consumption. It also demonstrated fast onset and prolonged sensory and motor block. We recommend uses of intrathecal neostigmine with plain bupivacaine as an adjuvant for lower limb orthopedic surgery.

\section{Acknowledgements}

We would like to thank Addise Ababa University for financial support and the study participants.

\section{Conflict of interest}

Author declares that there is no conflict of interest.

\section{References}

1. Pandey V, Mohindra BK, Sodhi GS. Comparative evaluation of different doses of intrathecal neostigmine as an adjuvant to bupivacaine for postoperative analgesia. Anesth Essays Res. 2016;10(3):538-545.

2. Ataro G, Bernard M. Effectiveness of Caudal Epidural Block using Bupivacaine with Neostigmine for Pediatric Lower Extremity Orthopedic Surgery in Cure Ethiopia Children's Hospital. J Anesth Clin Res. 2014;5(12):479.

3. Yoganarasimha N, Raghavendra TR, Radha MK. A clinical study of perioperative effectiveness of adjuvant Neostigmine with intrathecal Bupivacaine for lower abdominal surgeries. Journal of Dental and Medical Sciences. 2012;2(3):35-39. 
4. Faiz SH, Rahimzadeh P, Sakhaei M, et al. Anesthetic effects of adding intrathecal neostigmine or magnesium sulphate to bupivacaine in patients under lower extremities surgeries. J Res Med Sci. 2012;17(10):918-922.

5. Jain A, Jain K, Bhardawaj N. Analgesic efficacy of low-dose intrathecal neostigmine in combination with fentanyl and bupivacaine for total knee replacement surgery. J Anaesthesiol Clin Pharmacol. 2012;28(4):486-490.

6. Kayalha h, Mousavi Z, Sadat BA, et al. The effects of intrathecal neostigmine added to bupivacaine on postoperative analgesic requirement in patients undergoing lower limb orthopedic surgery. Middle East $J$ Anaesthesiol. 2015;23(2):199-204.

7. Yoganarasimha N, Raghavendra TR, Amitha S, et al. A comparative study between intrathecal clonidine and neostigmine with intrathecal bupivacaine for lower abdominal surgeries. Indian J Anaesth. 2014;58(1):43-47.

8. Kamali A, Shokrpour M, Vatanpour K, et al. Midazolam versus Neostigmineadding to Lidocaine in Post Operation Pain in Colporrhaphy Surgery in Spinal Anesthesia. Journal of Family and Reproductive Health. 2012;6(2):79-83.

9. Joshi Khadke S, Khadke VV, Patel SJ, et al. Efficacy of spinal additives neostigmine and magnesium sulfate on characteristics of subarachnoid block, hemodynamic stability and postoperative pain relief: A randomized clinical trial. Anesth Essays Res. 2015;9(1):63-71.

10. Lauretti GR. The evolution of spinal/epidural neostigmine in clinical application: Thoughts after two decades. Saudi J Anaesth 2015;9(1):71-81.

11. Chittora SP, Ahmed F, Sharma R. A comparative analysis of neostigmine as an additive to lignocaine for postoperative analgesia in intrathecal and epidural anesthesia. Indian J Anaesth. 2003;47(3):185-189.

12. Martinez KA, Snyder CF, Malin JL, et al. Is race/ethnicity related to the presence or severity of pain in colorectal and lung cancer? J Pain Symptom Manage. 2014;48(6):1050-1059.

13. Bhosle SS. Intrathecal Nalbuphine: An Effective Adjuvant for Post-Operative Analgesia. Innovative Journal of Medical and Health Science. 2014:4(2).

14. Marzieh Khezri MB, Tahaei E, Atlasbaf AH. Comparison of postoperative analgesic effect of intrathecal ketamine and fentanyl added to bupivacaine in patients undergoing cesarean section: a prospective randomized double-blind study. Middle East J Anaesthesiol. 2016;23(4):427-436.

15. Gupta S. Postoperative analgesia with intrathecal neostigmine; two different doses of $75 \mu \mathrm{gms}$ and $50 \mu \mathrm{gms}$ with heavy bupivacaine. Internet J Anesthesiol. 2010;25(1):1-7.
16. Akanmu OA. Comparison of Analgesic Effects of Intrathecal Fentanyl and Midazolam in Orthopaedic Lower Extremity Surgery. UNILAG Journal Basic Medical Sciences. 2013:1(2).

17. Bogra J, Arora N, Srivastava P. Synergistic effect of intrathecal fentanyl and bupivacaine in spinal anesthesia for cesarean section. BMC Anesthesiol. 2005;5(1):5

18. Cowan CM, Kendall JB, Barclay PM, et al. Comparison of intrathecal fentanyl and diamorphine in addition to bupivacaine for caesarean section under spinal anaesthesia. Br J Anaesth. 2002;89(3):452-458.

19. Akanmu ON, Soyannwo OA, Sotunmbi PT, et al. Analgesic Effects of Intrathecally Administered Fentanyl in Spinal Anaesthesia for Lower Limb Surgery. Maced J Med Sci. 2013;6(3):255-260.

20. Banihashem N, Hasannasab B, Esmaeili A, et al. Addition of Intrathecal Magnesium Sulfate to Bupivacaine for Spinal Anesthesia in Cesarean Section. Anesth Pain Med. 2015;5(3):e22798.

21. Vasure R, Ashahiya ID, Mahendra R, et al. Comparison of Effect of Adding Intrathecal Magnesium Sulfate to Bupivacaine Alone and Bupivacaine-Fentanyl Combination during Lower Limb Orthopedic Surgery. Int J Sci Stud. 2016;3(10):141-146.

22. Solaiappan B, Jeevarathnam R. Comparative study of intrathecal neostigmine and clonidine. J Evolution Med Dent Sci. 2016;5(57):3917-3925.

23. Bhar D, RoyBasunia S, Das A, et al. A comparison between intrathecal clonidine and neostigmine as an adjuvant to bupivacaine in the subarachnoid block for elective abdominal hysterectomy operations: A prospective, double-blind and randomized controlled study. Saudi J Anaesth 2016;10(2):121-126.

24. Shakya ML, Yadav AS, Dwivedi S. Comparative Evaluation of Intrathecal Neostigmine with Intrathecal Fentanyl for Post-operative Pain Relief. Int J of Sci Stud. 2016;4(5):168-171.

25. Biswas BN, Rudra A, Bose BK, et al. Intrathecal fentanyl with hyperbaric bupivacaine improves analgesia during caesarean delivery and in early post-operative period. Indian J Anaesth. 2002;46(6):469-472.

26. Singh H, Yang J, Thornton K, et al. Intrathecal fentanyl prolongs sensory bupivacaine spinal block. Can J Anaesth. 1995;42(11):987-991.

27. Bhat M, Ommid M, Gupta A, et al. Evaluation of intrathecal neostigmine in different doses added to bupivacaine for postoperative analgesia. Sri Lankan Journal of Anaesthesiology. 2011;19(1):33-38. 